\title{
Por uma Via Não Homonacionalista: a Criminalização de Corpos como Política Discursiva
}

\author{
Yago Vieira de Oliveira Almeida ${ }^{1}$
}

\section{Resumo}

Este artigo oferece uma leitura pós-colonial sobre o fenômeno da tentativa de criminalização de minorias sexuais e de gênero na República Democrática de Uganda, desde o período de 2009. Enquanto o processo em questão foi mobilizado não somente, mas também por práticas transnacionais,discursos reiterados por agentes estatais e agências intergovernamentais insistem em visualizá-lo como de natureza endógena. A incorporação desse discurso culmina, em última medida, em sanções e políticas de humilhação a nível global que negam, ou melhor, não verbalizam a participação exógena dessa tentativa. Com a mobilização de contribuições teóricas pós-coloniais e do campo de estudos da Análise do Discurso (AD), identifica-se como se constrói a responsabilização de sujeitos ugandenses e, em particular,o governo nacional de Uganda - comunidade sociopolítica vista primariamente pelo prisma da matriz africana - nesta iniciativa. Por sua vez, a interpretação monolítica supracitada é possibilitada pelo ainda persistente sistema de representação responsável por conceber o sujeito não-europeu em um espaço-tempo de atraso, em oposição ao parâmetro do modelo vigente de Estado-nação, historicamente construído por agentes políticos do Norte Global. Nesse sentido, o argumento central do artigo consiste em explanar, portanto, a dimensão complexa e transnacional envolvida no processo, não contemplada, dessa maneira, por atores da comunidade internacional no âmbito de suas práticas sociais.

Palavras-chave: Análise do Discurso, Sexualidade, Gênero, Criminalização, Uganda

\section{Abstract}

This article offers a postcolonial reading regarding the attempt on criminalization aimed at sexual and gender minorities in the Democratic Republic of Uganda since 2009. While the process in question was mobilized not only - but also by transnational practices - discourses reiterated by state representatives and intergovernmental agencies insist on visualizing it as endogenous in nature. The incorporation of this discourse results, ultimately, in sanctions and policies of humiliation at a global level that deny, or rather, do not verbalize the exogenous participation of this attempt. With the mobilization of postcolonial theoretical contributions and the Discourse Analysis field of study, one identifies how the accountability of Ugandan subjects is constructed, and in particular, the national government of Uganda - a socio-

\footnotetext{
${ }^{1}$ Graduado em Relações Internacionais pela Universidade Federal Rural do Rio de Janeiro e Pesquisador Assistente associado ao Observatório dos Países de Língua Oficial Portuguesa (OPLOP). E-mail: oliveira.yagovieira@gmail.com
} 
political community seen primarily by the prism of the African matrix in this initiative. In turn, the monolithic interpretation mentioned above is possible by the still persistent system of representation that conceives the non-European subject in a space-time of delay, as opposed to the parameter of the current model of nation-state, historically constructed by political agents from the Global North. Therefore, the central argument of the article is to explain the complex and transnational dimension involved in the process, not contemplated by actors of the international community in its social practices.

Key words: Discourse Analysis, Sexuality, Gender, Criminalization, Uganda

\section{Introdução}

O presente trabalho se ateve ao aprofundamento sobre o processo de análise em torno da criminalização de minorias sexuais e de gênero na República de Uganda, território do extenso e multifacetado continente africano. O reconhecimento do avanço de legislações de vigilância sexual sobre corpos e a ausência de um discurso minimamente explicativo sobre essas práticas políticas, incentivadas e implementadas por países como Uganda e Estados Unidos, implicam na necessidade de estudo sobre as dinâmicas que resultam em legislações predatórias a corpos particulares de forma cíclica. Como um ciclo histórico, pois apesar da presença milenar de práticas como a homossexualidade, sociedades acabam por demonizar o que não se encontra pela via do que pensam ser o "normal", como foi o caso da perseguição em Auchwitz, em Uganda, nos Estados Unidos e, atualmente, no Brasil, este como o país com os maiores índices de assassinato de ódio a transexuais e travestis na contemporaneidade. ${ }^{2}$

Ao notar a repetição de discursos homonacionalistas por parte da sociedade e de ativistas da comunidade queer quando deparados com o ódio deflagrado a membros de sua comunidade em países africanos, essa percepção se desdobra na incorporação da rigorosa divisão entre interno e externo calcada em campos como a Geopolítica e as Relações Internacionais, o que dificulta a identificação de procedimentos históricos, complexos e discursivos (WALKER; RIBEIRO; 2015). Esse é o caso da internacionalização de grupos conservadores - objeto desta pesquisa - que saem de países como os Estados Unidos com missão civilizatória a países como Uganda.

Apesar da extensa participação de grupos cristãos norte-americanos no processo de criminalização de minorias sexuais e de gênero em Uganda, ocorrido desde março de 2009, tanto pelo financiamento a igrejas e projetos específicos durante o embate cultural da legalização ou não do casamento igualitário no âmbito religioso, como pela difusão discursiva

\footnotetext{
${ }^{2}$ Os dados são fornecidos pela ONG Grupo Gay da Bahia e podem ser acessados pelo seguinte endereço eletrônico: https://homofobiamata.files.wordpress.com/2017/01/relatc3b3rio-2016-ps.pdf
} 
e lobbying com políticos envolvidos na legislação que buscou minar os direitos LGBTQ em uma esfera cidadã mais ampla, pouco se debate sobre a produção complexa e internacional desse processo de tentativa de criminalização.

Nesse sentido, nota-se a ausência de uma investigação crítica transdisciplinar que envolva sexualidades, gêneros e territorialidades pela ótica crítica das Ciências Humanas, o que inclui, neste caso, o campo das Relações Internacionais, demarcado pelo comprometimento estado-cêntrico, a partir da naturalização de conceitos provincianos e historicamente particulares, apresentados de forma universalista. ${ }^{3}$

É por esse caminho que essa pesquisa problematizará a rigorosa divisão entre interno e externo proposta pelo movimento pós-estruturalista e pós-colonialista das Relações Internacionais, concebendo categorias discursivas como o "Estado-nação", "fronteiras" e espaço como culturalmente e historicamente particulares. As proposições ditas tradicionais, tais como as neorrealistas e liberais não sustentam uma discussão complexa como a de corpos criminalizados na República de Uganda, justamente por incorporar o Estado como sujeito de referência e o reificar em detrimento das pessoas.

A partir dessa mobilização, a análise aponta para o processo de financiamento de ideias e projetos protagonistas no reforço da perseguição jurídica e social em Uganda por meio de um mapeamento discursivo e de dados. Longe de sustentar que são eles - os grupos norte-americanos envolvidos no processo de internacionalização - os únicos e supostamente sujeitos originais responsáveis por essas dinâmicas de criminalização - à medida que ugandenses também apresentam capacidade de agência e se mostram cúmplices desse processo - apresento como esses grupos estiveram presentes no processo gradual e sistemático de radicalização do projeto de lei e práticas políticas, apontando o caráter complexo e multidimensional de um fenômeno contemporâneo e impossibilitado de ser estudado pelas perspectivas ditas tradicionais das Relações Internacionais.

A presente pesquisa também sustenta a seletividade e a interpretação de cunho colonialista - aliada ao fenômeno do homonacionalismo, como designado por Jasbir K. Puar

\footnotetext{
${ }^{3}$ Rob Walker (2011) produziu uma minuciosa reflexão sobre as práticas acadêmicas no âmbito da pretensa disciplina de Relações Internacionais (RI), vista pelo autor como um fruto de teorias políticas resultantes de um processo histórico em particular, já suplantado por outra temporalidade. Segundo Walker, a perspectiva Estadocêntrica mobilizada pelas análises ditas "tradicionais", aliada à epistemologia positivista contemporânea na área das RI, não prioriza o questionamento sobre conceitos-chave como "nação", "soberania estatal" e "fronteiras". Repensar essas estruturas e reconhecer seu caráter historicamente particular é fundamental. Mesmo que para identificar dinâmicas mais complexas e contemporâneas envolvidas por essas concepções, tais como a rigorosa divisão entre interno e externo, processos historicamente contingentes e discursivos.
} 
(2015) - sobre o processo ocorrido em Uganda em razão de suas raízes de caráter internacional. Compreendido acriticamente como um fenômeno endógeno pelas elites políticas e discursos midiáticos, a tentativa de criminalização mostrou ser entendida por agências intergovernamentais como as Nações Unidas pela via do discurso do atraso. Calcadas na inclusão da defesa livre de liberdade e direitos da comunidade LGBTQ como parte fundamental da ideia de modernidade eurocêntrica, territorialidades como as de Uganda são vistas por essas lentes como espaços de povos e ideias atrasadas, o que mostra a urgência de uma perspectiva híbrida e não monolítica não somente, mas também pelas Relações Internacionais quando analisamos fenômenos culturais e históricos.

\section{A construção da lei enquanto um fenômeno complexo}

Enquanto o processo de criminalização de minorias sexuais e de gênero na República de Uganda, durante o intervalo de 2009 - ano do primeiro rascunho do projeto de lei - e 2014 - ano da aprovação e da posterior derrubada da lei pelo Corte Suprema do país - foi projetada internacionalmente de forma a entender o processo pela via monolítica, ativistas e pessoas perseguidas pela passagem reconhecem os efeitos de grupos externos nesse processo.

A elaboração de uma lei desse porte, responsável por incutir o controle da sexualidade no território não é limitada ao século XXI, nem de referência estrita ugandense, apesar de discurso contrário. O artigo 145 do Código Penal de Uganda, implementado em 1950 sob o controle do domínio colonial britânico, aponta a internalização de práticas "sodomitas" como abomináveis e, portanto, dignas de penalização. ${ }^{4}$ Após a descrição da "sodomia" como uma prática contrária à "ordem da natureza", no âmbito da seção intitulada "Ofensas Contra a Moralidade", o processo de vigilância e punição a corpos não incorporados pelo tropo heteronormativo é reificado pelo artigo seguinte, a partir do apontamento da possibilidade de encarceramento de até 7 anos em razão dessas práticas, vistas pela ótica da heteronormatividade.

De fato, poucos são os estudos que se debruçam sobre a correlação da homossexualidade, sua patologização enquanto identidade sexual e a expansão histórica imperial, ou mesmo como a sexualidade foi fator preponderante à sedimentação da colonização(ALDRICH, 2003).Ainda, apesar da potencial correlação da presente desumanização de LGBTQs em Uganda e a internalização da "sodomia" como categoria

\footnotetext{
${ }^{4} \mathrm{O}$ conteúdo do Código Penal em sua versão original pode ser acessado através do seguinte endereço eletrônico: http://www.icla.up.ac.za/images/un/use-of-force/africa/Uganda/Penal\%20Code\%20Act\%20Uganda\%201950.pdf
} 
pejorativa a partir de um aparato colonial, o afastamento para a análise da atual radicalização de ódio a esses sujeitos de sexualidade não necessariamente requer um distanciamento temporal longínquo. Na verdade, a lógica transpassada pela necessidade da expansão imperial britânica em deslegitimar afetos e possibilidades de corpos sob a articulação do Estado e de uma visão judaico-cristã particularmente fundamentalista se revela ainda presentes na contemporaneidade. Nesses contextos, a instrumentalização da religião e a visualização do Outro racial são as duas lógicas fundantes e comuns nessas interações, o que é reconhecido pelo rastreamento da lei, neste caso em particular.

A construção do recente projeto de lei de 2009, iniciada por David Bahati, integrante do parlamento de Uganda e membro do partido político Movimento de Resistência Nacional (MRN), foi marcada desde então pela atuação conjunta norte-americana. Kapya Kaoma, pesquisador e bispo em Uganda na época, dedicou-se a compreender a dinâmica de incitamento ao ódio estabelecida por líderes políticos e religiosos vindos dos Estados Unidos desde então. ${ }^{5}$ Apesar da influência americana em políticas africanas remontarem a décadas anteriores, a emergência da radicalização de ódio projetada na lei pode ser inicialmente traçada a partir da ocorrência de um seminário em Kampala, em março de 2009, intitulado "Exposing the Truth behing homossexuality and the Homosexual Agenda". Nesta ocasião, estiveram presentes figuras como Scott Lively, político e líder religioso estadunidense, e autor do livro "The Pink Swastika: Homosexuality in the Nazi Party", no qual é defendida a suposta tese de participação homossexual no âmbito do sistema nazista.

Lively não somente engajou-se ativamente durante o seminário, mas também agiu no espaço de discussão política do parlamento de Uganda. Em 9 de março do mesmo ano, de acordo com seu relato, "50 to 100 persons [were] in attendance, including numerous legislators and the minister of ethics and integrity [with] whom I enjoyed a personal chat. "Posteriormente, no dia 15, Kaoma relata a ocorrência de um encontro estratégico entre os membros do parlamento visando solucionar a problemática da designada "agenda homossexual internacional". Logo depois, no dia 29 de Abril, o primeiro rascunho do projeto de lei é introduzido e discutido pelo representante Bahati. Inicialmente elaborado e focalizado na pena de morte, em 2013, a lei foi modificada para a penalidade máxima de prisão perpétua.

\footnotetext{
${ }^{5}$ Em Colonizing African Values, Kapya Kaoma desmembra as relações de financiamento entre grupos cristãos conservadores, legisladores e líderes locais de Uganda. Kaoma, vindo de Zâmbia, morava em Uganda na época de sua pesquisa e seu trabalho como bispo na região. No entanto, após o reconhecimento dos resultados de seu trabalho, sobretudo pelo governo ugandense, de onde sofreu duras críticas pela comunidade internacional, foi obrigado a fugir do país e não é mais autorizado a retornar, residindo atualmente em Boston, EUA.
} 
Segmentada pela tipificação de "homossexualidade" e "homossexualidade agravada", a portabilidade do vírus HIV também foi enquadrada no caso de agravamento e correlacionada à interpretação da pessoa infectada como um sujeito de ameaça e não de direitos. ${ }^{6}$ Em 24 de Fevereiro de 2014, com críticas consistentes da comunidade internacional e, particularmente, de agências intergovernamentais de direitos humanos e do governo de Barack Obama em especial, o presidente Yoweri Musevini sancionou a lei. Esta foi posteriormente revogada pela Corte Suprema de Uganda em razão de falhas processuais de acordo com a decisão, em outubro do mesmo ano. Apesar da revogação, pouco se discutiu sobre o engajamento de sujeitos externos na apropriação da lei e na construção de discursos potencialmente favoráveis à formatação de atos jurídicos como o que consta nesta pesquisa.

\section{0 financiamento e a disputa cultural religiosa internacional}

A expansão e a materialidade do discurso de ódio a LGBTQs em Uganda emergem em um cenário de forte articulação entre o financiamento privado de grupos norte-americanos conservadores, compartimentalizado através de think tanks, ONGs e de igrejas que estejam alinhadas e/ou disciplinadas a defender uma interpretação especificamente fundamentalista da teologia cristã.

É possível argumentar que a crítica a igrejas e congregações visualizadas como progressistas no espectro da interpretação cristã persiste em parte do imaginário social religioso, especialmente pela demonização de práticas e ideias associadas ao campo sociopolítico do "comunismo" e todo o tipo de agenda associada a esse sistema de ideias, um potencial legado do período da Guerra Fria. O fenômeno de internacionalização de igrejas na região africana não é novo, mas aponta para esse período histórico, calcado simbolicamente pela discussão dos projetos político-econômicos socialistas e capitalistas. Durante o apartheid, um conjunto de igrejas apoiava a luta contra o regime racista na África do Sul. Em 1980, com a emergência de novas igrejas e movimentos renovados iniciaram-se ataques por parte de congregações rivais conservadoras e também norte-americanas às demais igrejas por identificarem sua simpatia pelo legado marxista. Apesar de tais ataques, as igrejas principais

\footnotetext{
${ }^{6}$ The Human Dignity Trust condensa de forma ilustre as implicações e os detalhes da lei, que podem ser acessados pelo seguinte endereço eletrônico: 
dos EUA gozaram de calorosas relações até recentemente, quando os conservadores usaram o testemunho social dessas igrejas sobre questões LGBTQs para encorajar as igrejas africanas a rejeitar sua ajuda financeira (KAOMA, 2013).

Entrevistado pela equipe de pesquisa de Kaoma, um professor queniano conta sobre a disputa de fundos no âmbito da sua universidade. Contrários à atuação da Igreja Episcopal, compreendida como progressista por grupos conservadores, "american conservatives have been in my office several times requesting that we cut ties with TEC and other progressive funders in exchange for their funds. They have succeeded in getting small colleges into their camp, but we have refused "7. (KAOMA, 2013, p. 9)

O padre Aaron Mwesigye, atualmente trabalhando no escritório do arcebispo Henry Orombi em Uganda, afirma que grupos conservadores religiosos vêm contribuindo com a remuneração e salários da equipe de trabalho da província desde 1998. Nesse sentido, a tese defendida por Kaoma ganha materialidade conforme nos apossamos do contexto de disputa e discursos dos sujeitos envolvidos. A ideia defendida de que ocorre uma exportação de guerras culturais já reproduzidas em território norte-americano para a região africana ganha especial sentido quando analisamos o discurso do documento de fundação do Instituto de Religião e Democracia (IRD). ${ }^{8}$

Think-tank de caráter cristão fundado em 1981, com apoio de projetos na República de Uganda, o IRD critica sistematicamente, em sua carta de fundação,a gestão de regimes totalitaristas marcados durante o século passado, entre os quais se destaca a Alemanha nazista e o regime stalinista da União Soviética. Apesar de reconhecerem o fim dos regimes totalitários, a organização enfatiza em seu discurso a persistente presença de Estados leninistas-marxistas, os quais devem ser combatidos em detrimento da alegada defesa da liberdade. Nota-se, portanto, o delineamento da associação entre o campo de ideias da esquerda política e um certo totalitarismo, instrumentalizando essa construção com vistas aplanos de ação subsequentes. Nas palavras do documento:

the struggle against communism in which we, and so many others, have been involved has been primarily a moral struggle. For in addition to the unspeakable

\footnotetext{
${ }^{7}$ Tradução livre: Norte-americanos conservadores estiveram em meu gabinete inúmeras vezes solicitando que cortássemos laços com a Igreja Episcopal e outros financiadores progressistas em troca de seus fundos. Eles foram bem-sucedidos ao conseguirem cooptar pequenos colegiados em favor de seus grupos, mas nós recusamos.

${ }^{8}$ A carta de fundação pode ser acessada através deste link: https://theird.org/about/founding-document/
} 
human suffering that communism caused its intent was itself evil. [...] The historic alternative to totalitarianism in the modern world is democracy. ${ }^{9}$

Cabe, assim, o questionamento: qual ou quais Estados podem e devem ser considerados não democráticos, de acordo com a avaliação da IRD? O mandato da organização, nesse sentido, é norteado pelo engajamento na defesa de sociedades democráticas e dos ensinamentos cristãos, estando os dois pilares intimamente associados e articulados por uma interpretação esquemática. Nesse contexto, a percepção de países e de regiões específicas como não democráticas assenta a atuação da organização, como pode ser visto pelo trecho a seguir:

The hard work of encouraging the consolidation of democratic regimes lies ahead. This is particularly the case for Eastern Europe and the former Soviet Union, but in Africa, Latin America, and Asia there are also societies in transition from authoritarianism toward democracy. They, too, demand our attention. Nor should we forget that in China and Cuba communist rulers have neither abandoned their ideology nor relinquished their power. ${ }^{10}$

A presente tese de Kaoma fica mais evidente quando analisamos o documento interno da IRD intitulado "Reforming America's Churches Project 2001 - 2004". ${ }^{11}$ Ao longo do documento, nota-se a crítica a igrejas de maior público-alvo e defensoras de agendas progressistas como lógica da organização. Além disso, o estabelecimento de relações com igrejas de linha ortodoxa em regiões africanas é assumido como meta de enfrentamento a igrejas progressistas como a Episcopal em um cenário global. Assim, o documento afirma:

The Episcopal Church is the most liberal-dominated denomination of the major three that we are targeting. Efforts to legitimize homosexual unions, for example, have only narrowly been defeated. But conservatives are successfully building direct connections through their local dioceses and mission groups to the vibrant, orthodox Anglican churches in Africa and Asia. Conservative overseas bishops are coming to the rescue of troubled American dioceses that are beset by inept leadership. ${ }^{12}$

\footnotetext{
${ }^{9}$ Tradução livre: A luta contra o comunismo na qual nós, assim como muitos outros, vem se envolvendo, vem sendo primeiramente uma luta moral. Além do incomunicável sofrimento humano causado pelo comunismo, seu propósito era o próprio Mal. A Alternativa histórica ao totalitarismo no mundo moderno é a democracia.

${ }^{10}$ Tradução Livre: $\mathrm{O}$ difícil trabalho de encorajar a consolidação de regimes democráticas permanece adiante. Esse é o caso particular do caso da Europa oriental e a antiga União Soviética, mas na África, América Latina e Ásia, também há sociedades transitando do autoritarismo para a democracia. Elas, também, demandam nossa atenção. Devemos nos lembrar que na China e cuba, líderes comunistas não abandonaram sua ideologia nem se desfizeram de seu poder.

${ }^{11}$ Disponível em 〈http://www.theocracywatch.org/internal_document_ird.html〉

12 Tradução livre: A Igreja Episcopal é a denominação mais dominada pelos liberais dentre os três maiores que estamos enfrentando. Os esforços para legitimar as uniões homossexuais, por exemplo, foram derrotados por pouco. Mas os conservadores estão construindo conexões diretas através de suas dioceses locais e grupos missionários para as vibrantes igrejas anglicanas ortodoxas na África e na Ásia. Bispos conservadores do
} 
Diante desse contexto, através do exame desses discursos, conclui-se que o espaço africano se torna um referencial nas disputas sobre o avanço ou não de agendas específicas. A narrativa de embate é reconhecida pelo seguinte enunciado: "the battle is clearly joined. Now, more than ever, it is necessary to redouble the IRDs efforts" ${ }^{\prime 13}$. Apesar da organização negar no documento de fundação sua articulação contra um espectro ideológico em particular, seja o campo político de esquerda ou de direita, notamos a posição contrária no posicionamento interno, como pode ser visualizado através da seguinte afirmação:

\begin{abstract}
While there are encouraging signs that efforts such as the IRDs have lessened the impact of the Religious Left, we can expect renewed vigor of radical religious voices in the next four years. The Clinton era muted some of the religious leaders, who did not want to criticize a friendly Democratic Administration, even though their own views were actually further to the Left. We can anticipate that the strident polarization of the 1980s will reappear in the next four years. ${ }^{14}$
\end{abstract}

Deve-se dizer logo de início que a disputa pelo sentido da palavra família delineia-se nesses documentos, em razão da contingência histórica de movimentos cristãos conservadores no tocante às lutas de movimentos LGBTQs pela legalização do casamento igualitário. Esse aspecto confirmou-se anos depois com a decisão histórica de inúmeras cortes supremas a nível global. Em países historicamente marcados pela tradição de um forte movimento religioso fundamentalista como os Estados Unidos da América e a República da Argentina, a legalização do casamento igualitário ocorreu, respectivamente, em 2015 e 2010. Embora legalizado recentemente, configuram-se como um desdobramento de anos de resistência e, não ao acaso, a identificação dessa "ameaça" por igrejas ortodoxas desde tempos remotos.

\title{
Narrativas: a linguagem enquanto representação
}

O desmembramento dos discursos reproduzidos durante o período de construção da lei, bem como aqueles de governantes e representantes de agências intergovernamentais, permite-nos extrair o modus operandis da interação de sujeitos de posições privilegiados por

ultramar estão chegando ao resgate de dioceses americanas com problemas que são acometidas por lideranças inaptas. Disponível em: http://www.theocracywatch.org/internal_document ird.html

${ }^{13}$ Tradução livre: A batalha está nitidamente formada. Agora, mais do que nunca, é necessário dobrar os esforços da IRD.

${ }^{14}$ Tradução livre: Embora haja sinais esperançosos de que esforços como aqueles tomados pelo IRD diminuíram o impacto da esquerda religiosa, podemos esperar um vigor renovado de vozes religiosas radicais nos próximos quatro anos. A era Clinton silenciou alguns dos líderes religiosos, que não queriam criticar uma administração democrática amigável, mesmo que seus próprios pontos de vista fossem realmente mais à esquerda. Podemos antecipar que a polarização estridente da década de 1980 reaparecerá nos próximos quatro anos. 
uma condição social e geopolítica particular e do "Outro" racializado, ainda receptor do impacto colonial não distante.

É nesse sentido que Homi Bhabha (1980), incorporando segundo Marcelo Souza (2008) uma metafísica da generalidade, ao identificar no uso de um pensamento colonial de colonizador versus colonizado e a pressuposição da diferença arbitrária entre inferior e superior marcada em subjetividades, nos indica o lugar do discurso como uma modalidade fundamental às práticas sociais. A demanda contingente por um discurso de cunho híbrido se revela fundamental frente ao ainda persistente elemento do estereótipo do discurso colonial a identidade atemporal fixa de atraso do sujeito africano -, vislumbrado pela crítica de Bhabha e ainda persistente na lógica do funcionamento de instituições e discursos.

Mikhail Bakhtin (1930) também nos serve de relevante reflexão acerca dessa temática por uma ótica disciplinar do campo discursivo. Dedicando-se extensivamente sobre a área da linguagem, o autor enxerga as limitações derivadas do foco restrito dos estudos da linguística, limitadas ao sistema imanente da língua. Atribuindo importante valor à enunciação enquanto dimensão da linguagem, Bakhtin identifica a matéria linguística como apenas uma parte do enunciado; incorporando uma outra dimensão, a não-verbal, correspondente ao contexto da enunciação(BRANDÃO, 1991). A interpretação sobre a interação social, calcada na relação com o Outro, como determinante à construção do significado, resulta, portanto, da esfera social. A palavra, em sua natureza plurivalente e enquanto elemento representante da realidade, incorpora em sua dimensão material a ideologia, atribuindo-se o sentido. Ela é vista, então,como signo ideológico.

Destacando-se o caráter semântico do discurso, o sentido é extraído sob a perspectiva de coexistência e assentamento sobre outros. Assume-se assim um postulado geral e amplamente incorporado pelo campo da Análise do Discurso (AD): os discursos são atravessados e materializados pelos demais. A análise sobre a interação entre as distintas formações discursivas, nesse sentido, é fundamental.

A partir da lente discursiva, podemos analisar o discurso de Lively Scot durante a conferência em Kampala, Uganda, com o seguinte pronunciamento: "I know more about this [homosexuality] than almost anyone in the world ... The gay movement is an evil institution. The goal of the gay movement is to defeat the marriage-based society and replace it with a culture of sexual promiscuity." 15

\footnotetext{
${ }^{15}$ Tradução livre: Conheço mais sobre isso [a homossexualidade] do que qualquer outra pessoa no mundo... O movimento gay é uma instituição diabólica. O objetivo do movimento gay é destruir a sociedade baseada no casamento e substitui-la por uma cultura de promiscuidade sexual.
} 
Conforme a narrativa de Lively, assumida através da demonização da homossexualidade, a projeção de seu papel enquanto conhecedor do fenômeno "mais do que qualquer outra pessoa no mundo"revela a percepção do público-alvo como desconhecedor da temática abordada, como uma matéria desconhecida e não comum àquela realidade. Retomando o contexto de produção desse discurso, em Uganda, localizada em um espaço historicamente associado ao atraso e ao não ocidental, nota-sea ainda persistente lógica racial do sujeito branco como aquele que detém o conhecimento necessário e, sobretudo, apropriado, em contraposição ao sujeito de identidade africana, aquele que demandaria o ensino.

A apresentada narrativa de Lively remete, assim, ao seu contexto de enunciação, ressaltando a necessidade de investigação sobre a própria natureza do discurso. De acordo com Michel Foucault (1969), o discurso é um conjunto de enunciados relativos a uma mesma formação discursiva, na qual se exerce a confrontação, um local de disputa. Desse modo, a presença de um referencial - entendido como condição de possibilidade de aparecimento e de desaparecimento de referenciais destacados através do enunciado - é elemento constante. Assume-se a equivalência do discurso à construção de narrativas, ou seja, ele é moldado pela capacidade de enunciação a partir da realidade de sujeitos históricos e sociais, atravessados pela ideologia. Viabiliza-se o passar da mensagem sob uma formação discursiva específica e moldada subjetivamente, assentada, portanto, no recorte de uma realidade particular de um espaço-tempo único.

Dessa forma, o discurso e o sujeito estão ligados pelo elemento da dispersão. O sujeito é compreendido como uma função vazia, indicando a possibilidade de atuação em múltiplas frentes e o fazer sob condições variáveis dependendo da natureza eminentemente dispersa. Conclui-se que existe uma gama de papeis a serem escolhidos para a interpretação teatral daquele que, atravessado pelos aparelhos ideológicos - escola, igreja, espaço político -, é interpelado como sujeito.

Assim, a reprodução do tom admitido por Lively é atravessado por outras narrativas. O presidente de Uganda, Yoweri Musevini, na época, afirmou "I hear European homosexuals are recruiting in Africa...we used to have very few homosexuals traditionally". ${ }^{16}$ Nesse contexto, a noção de que a presença de práticas de mesmo sexo não é inerente ao continente africano é persistente, tanto por parte de sujeitos locais como não locais. Em entrevista à Agência de notícias Reuters, David Bahati, autor da lei informalmente conhecida como Kill

16 Tradução livre: Ouço dizer que homossexuais europeus estão recrutando no continente africano... costumávamos a ter pouquíssimos homossexuais, tradicionalmente. 
the gays, afirmou em resposta às críticas do Banco Mundial"[the law] is very much worth it because it will protect our values. I think a society that has no moral values is a contradiction to development". ${ }^{17}$

Marc Epprecht (2008) busca investigar através desse aparato sócio discursivo como emerge o conceito de África heterossexual e os efeitos dessa perspectiva na construção das políticas africanas. No caso da expansão dos casos da AIDS e infecção por HIV na década de 80, Epprecht (2008) aponta para os impactos decorrentes dessa percepção, sobretudo pela comunidade científica, na fragilidade da resposta à emergência por parte de programas de saúde em territorialidades africanas. A possibilidade de contágio via sexual entre homens era simplesmente descartada em alguns casos, constituindo-se como um dos elementos explicativos para a expansão da doença no continente. Matt Swagler (2009), em revisão crítica sobre a obra de Epprecht, aponta:

\begin{abstract}
Although accounts of early European sailors and plunderers alluded to the existence of non-heterosexual practices in Africa, Epprecht notes that with the colonial scramble for Africa in the late nineteenth and early twentieth centuries, a "collective silence descended on the topic." New ruling-class ideas in Europe about the existence of a distinct group of diseased "homosexuals" mixed with racist conceptions of Africans. Since colonial writers perceived Africans as "uncivilized and close to nature" they also saw them as incapable of exerting control over their natural "heterosexual instincts." Early observations of gender or sexual realities in Africa which seemed to contradict this stereotype were generally blamed on the influence of Arabs, Turks, or Muslims - all groups that European authorities saw as having succumbed to sexual decadence, (i.e. homosexuality), and effeminacy among men. ${ }^{18}$
\end{abstract}

Estudiosos como Stephen Murray e Will Roscoe (1998) oferecem um relato detalhado da existência de práticas não convencionais em territórios africanos. ${ }^{19}$ Thabo Msibi, pesquisador da Universidade de Kwazulu-Natal, aponta para as contradições incutidas no imaginário sociodiscursivo como o reproduzido por Lively a partir da documentação sobre

\footnotetext{
${ }^{17}$ Tradução livre: a lei é muito recompensadora porque protegerá nossos valores. Penso que uma sociedade que não tenha valores morais é uma contradição ao desenvolvimento.

${ }^{18}$ The Myth of "Heterosexual Africa" Review. Disponível em <http://isreview.org/issue/71/myth-heterosexualafrica> Acesso em 16/07/2017

Tradução livre: Embora os relatos dos primeiros marinheiros e saqueadores europeus aludissem à existência de práticas não heterossexuais na África, Epprecht observa que, com a disputa colonial para a África no final do século XIX e início do século XX, um "silêncio coletivo desceu sobre o tema". Novas ideias prevalecentes na Europa surgiram sobre a existência de um grupo distinto de "homossexuais" doentes, misturados com concepções racistas de africanos. Uma vez que os escritores coloniais perceberam os africanos como "incivilizados e próximos da natureza", eles também os viram incapazes de exercer controle sobre seus "instintos heterossexuais" naturais. As primeiras observações de gênero ou realidades sexuais na África que pareciam contrariar este estereótipo eram geralmente culpadas da Influência de árabes, turcos ou muçulmanos - todos os grupos que as autoridades europeias consideraram ter sucumbido à decadência sexual (ou seja, homossexualidade) e à efeminação entre os homens.

${ }^{19} 6$ Murray, S. and Roscoe, W., Boy-Wives and Female Husbands: Studies of African Homosexualities (1998)
} 
práticas de mesmo sexo em territorialidades africanas. ${ }^{20}$ Ainda assim, apesar de extensos relatos antropológicosdecorridos do período pré-colonial e colonial em territórios africanos, a narrativa deapagamento sobre a existênciade práticas sexuais entre pessoas de mesmo gênero - grosseiramente intitulada de "homossexualidade" ${ }^{21}$ na contemporaneidade -ainda persiste no continente africano, fortalecendouma imagemde umaÁfrica heterossexual como resultado da exclusão de sujeitos.

Ainda, Swaggler (2009) revela a importância do trabalho de Precchet ao problematizar a internalização dessa lógica pelos próprios movimentos anticolonialistas:

\begin{abstract}
By the end of the Second World War, black African revolutionaries and nationalists began to mount an increasingly effective challenge to foreign rule. Epprecht argues that despite their ability to debunk many of the racist ideas promoted by colonialism and apartheid, writers and leaders like Jomo Kenyatta, Julius Nyerere, and Frantz Fanon ultimately remained complicit in perpetuating the myth of a "heterosexual Africa." For many anti-colonialists, restoring African self-respect, and more specifically African "manhood," became a necessary first step after years of adult African men and women being treated, and referred to, as "boys" and "girls" by their white bosses and authorities. ${ }^{22}$
\end{abstract}

Dessa maneira, a afirmação do presidente ugandense Musevine (2014) revela sua dimensão enquanto produto histórico quando explica a lei:"the measure was provoked by arrogant and careless western groups that are fond of coming into our schools and recruiting young children into homosexuality". ${ }^{23}$ A ONG Sexual Minorities in Uganda (SMUG), responsável pelo trabalho de resistência à perseguição de LGBTQs no país, vem documentando e presenciando a ofensiva contra as minorias sexuais desde a emergência do projeto de lei. David Kato, na época coordenador da equipe de advocacy da organização, foi assassinado em 2011 quando havia iniciado seu trabalho com a organização visando a derrubada da lei.

\footnotetext{
${ }^{20}$ Msibi, T., 'The Lies We Have Been Told: On (Homo) Sexuality in Africa' in Africa Today, Vol. 58, No. 1 (2011), p. 99

${ }^{21}$ A utilização do termo "homossexualidade" e/ou "homossexual" para descrever as práticas sexuais ocorridas entre pessoas de mesmo gênero é anacrônica, na medida em que a formação de identidades sexuais, incluindo a da figura homossexual é uma invenção recente, como bem aponta Foucault em A História da Sexualidade.

22 Tradução livre: No final da Segunda Guerra Mundial, revolucionários e nacionalistas africanos negros começaram a montar um desafio cada vez mais consistente ao domínio estrangeiro. Epprecht argumenta que, apesar de sua capacidade de desconsiderar muitas das idéias racistas promovidas pelo colonialismo e o apartheid, escritores e líderes como Jomo Kenyatta, Julius Nyerere e Frantz Fanon, continuaram sendo cúmplices na perpetuação do mito de uma "África heterossexual". Para muitos anti-colonialistas, restaurar a autoestima africana e, mais especificamente, a "masculinidade" africana, tornou-se um primeiro passo necessário depois de anos de homens e mulheres adultos africanos serem tratados e referidos como "meninos" e "meninas" por seus chefes e autoridades brancas.

${ }^{23}$ Tradução livre: A medida foi provocada pela arrogância e descuidado de grupos ocidentais que insistem em vir em nossas escolas e recrutas jovens crianças para a homossexualidade.
} 
Frank Mugisha, Diretor-Geral da SMUG, em entrevista oferecida ao jornal investigativo britânico Independent, aponta "the [idea] of a gay agenda, of recruiting people to homosexuality - that language wasn't used in Uganda pre-2009. [Lively] made my work very difficult and was conspiring with my legislators, but [to Ugandans] he was like God himself. People were worshipping him as if he was from heaven". ${ }^{24}$

Nota-se que, ao mesmo tempo em que esses sujeitos são marcados através de seu espaço de origem - construído pelo signo ocidental -, são projetados também de forma a criticar agendas indicadas por esse mesmo espaço sociodiscursivo, ressaltando a natureza híbridadesses sujeitos, que assumem o título de sujeito do entre lugar, como reconhecido por Homi Bhabha (1980). Nesse sentido, as contradições são inerentes e impedem, portanto, o uso da via monolítica. Bhabha (1980) propõe uma nova perspectiva da cultura e busca desmantelar os binarismos identitários que marcam as análises socioculturais, aqueles que impedem a identificação de processos complexos, característicos de um mundo em que o global atravessa o local. Influenciado pela experiência da fronteira, o autor investiga através de "O Local da Cultura"a construção de sujeitos que não se identificam nem com Um nem com o Outro, embora marcados pelas temporalidades do pós e pré-moderno. Seu significado é produzido em um terceiro espaço, híbrido. Em suas palavras:

O que é teoricamente inovador e politicamente crucial é a necessidade de passar além das narrativas de subjetividades originárias e iniciais e de focalizar aqueles momentos ou processos que são produzidos na articulação de diferenças culturais. Esses "entre-lugares" fornecem o terreno para a elaboração de estratégias de subjetivação - singular ou coletiva - que dão início a novos signos de identidade e postos inovadores de colaboração e contestação, no ato de definir a própria ideia de sociedade. (BHABHA, 1998, p. 20)

\section{Visibilidades, políticas de humilhação e o pós-colonialismo como alternativa}

Essa seção final visa à exposição da visualização monolítica e categoricamente binária sobre o processo de criminalização de minorias sexuais e de gênero em Uganda por meio de uma abordagem pós-colonial. A não verbalização da articulação programática, financeira e política em torno do fenômeno estudado ao longo deste artigo nos leva aos seguintes questionamentos: De que forma líderes e programas políticos projetam a percepção sobre

\footnotetext{
${ }^{24}$ Tradução livre: “A ideia de uma agenda gay, de recrutamento de pessoas para a homossexualidade - essa linguagem não era mobilizada em Uganda antes de 2009. [Lively] dificultou em muito meu trabalho e estava conspirando com meus legisladores, mas [para os ugandenses] ele era o próprio Deus. As pessoas o estavam venerando como se ele tivesse vindo do céu." Entrevista disponível em: http://www.independent.co.uk/news/world/africa/how-uganda-was-seduced-by-anti-gay-conservativeevangelicals-9193593.html Acesso em 16/08/2017
} 
essas dinâmicas em suas formações discursivas? Há algum sistema de representação materializado nessas subjetividades e, por último,como visibilidades de sujeitos e nações contribuem nesse processo?

O desenvolvimento do enquadramento conceitual de "homonacionalismo", termo mobilizado por Jasbir K. Puar (2015), serve-nos como importante instrumento de análise à medida em que expõe as contradições e a apropriação de identidades sexuais pelo projeto de Estado-nação moderno. A tarefa de Puar (2015) consiste em apontar as contradições decorrentes da incorporação liberal de sujeitos de sexualidade pela figura do Estado-nação. O engajamento de nações na defesa da legalidade e de marcadores sociais positivos quanto à capacidade de navegação de LGBTQs pela política identitária nessas sociedadesproduzem narrativas de modernidade e progresso à custa da invisibilidade de Outros. A arquitetura do sistema, nesse sentido, é sustentada na verificação dos efeitos decorridos do sucesso de movimentos dessas minorias pela via dos aparelhos do Estado moderno. Nesse sentido, o homonacionalismo é rearticulado como um campo de poder e não como ou propriedade de qualquer Estado-nação, organização ou indivíduo. (PUAR, 2015, p. 299) Por esses termos, nota-se que o homonacionalismo torna-se prática estrutural do projeto de modernidade enquanto apropriação das sexualidades aos direitos humanos ancorando a legitimação de projetos de políticas externas autorizadas a agir em nome do "progresso" e em combate às estruturas do "atraso".

A materialização desse conceito é particularmente notável quando visualizamos a projeção do fenômeno de pinkwashing por parte de estruturas políticas historicamente assentadas na disputa pela legitimidade de práticas amplamente criticadas pela opinião pública, como o caso do controle de territórios palestinos pelo Estado de Israel. Ocorre que com a projeção cada vez crescente sobre sua figura enquanto um defensor amplo e recorrente dos direitos de sujeitos de sexualidade, muitas das práticas desses atores políticos anteriormente visualizadas como inegociáveis- permanecem não legitimadas, mas são, por vezes,flexionadas. Sendo assim, é comum a emissão de discursos de senso comum tais como: "Israel apresenta práticas colonialistas sobre o povo palestino, mas e quanto à homofobia desse povo [o palestino]quanto a gays e lésbicas?"

Nesses termos, Puar (2015) reconhece a exclusão de direitos que não aqueles das minorias de sexualidade e de gênero, como a inviabilização do imigrante como um sujeito de 
direitos à custa desse homonacionalismo, e como o caso de direitos trabalhistas às custas desse projeto. $^{25}$

Como resultado, a análise em torno de políticas de ameaça e sanções vindas de Estados conhecidos por suas legislações e amplas defesas discursivas de LGBTQs apresentase com um elemento contributivo para a apreensão da dimensão homonacionalista. As palavras de John Kerry, ex-secretário de Estado norte-americano durante a gestão de Barack Obama, são representativas como seguem: "you could change the focus of this legislation to black or Jewish and you could be in 1930s Germany or you could be in 1950s-1960s apartheid South Africa. It was wrong there egregiously in both places and it is wrong here."26

Com essas palavras, podemos levantar a reflexão sobre o espaço de proferimento do discurso político, demandante de omissões e de enunciados verbalizados possíveis de camuflar dinâmicas potencialmente problemáticas e, por isso, a mobilização da linguagem esquemática e estado-cêntrica. Como discutido por Patrick Charaudeau (2008), discurso e ação são dois componentes da troca social, carregando o ato de linguagem como uma dimensão assimétrica. $\mathrm{O}$ sujeito da linguagem demanda a existência do Outro com vistas ao seu próprio reconhecimento enquanto diferente e carregando em si seu próprio projeto de influência. Quando tratamos do discurso diplomático, fica evidente sua dimensão homogeneizadora e monolítica sobre os fenômenos internacionais, por isso, a recorrência da utilização do termo nação no discurso de Kerry e sua omissão quanto à natureza transnacional do fenômeno em questão.

Nesse contexto, a hipótese de que a percepção monolítica sobre o fenômeno é acompanhada de um sistema de representação forjador de um Ocidente como "avançado" é notada diante da permanência da associação do campo sócio-discursivo do atraso àqueles não incorporados pelo modelo de modernidade ancorado por nações europeias e a estadunidense modelos de sociabilidades LGBTQs na contemporaneidade. Assim, a não verbalização do engajamento de movimentos cristãos norte-americanos nessa empreitada é visto não somente como um efeito desse sistema, mas ainda marcado pelo discurso esquemático do "doméstico" e do "global". Como Marta Fernández (2011) nos aponta, a contribuição de Bhabha (1991)

\footnotetext{
${ }^{25}$ Jasbir K. Puar apresenta um caso emblemático em sua pesquisa. A revogação da política “Don’t ask, Don’t Tell”, conhecida pela proibição de homossexuais nas forças militares dos Estados Unidos, ocorreu no mesmo dia em que o Senado norte-americano negou o prosseguimento da lei DREAM (Development, Relief, and Education for Alien Minors), uma legislação que teria legalizado milhões de estudantes ilegais, permitindo-lhes aceder ao ensino superior e, ironicamente, listar-se nas forças militares. (PUAR, 2015, p. 301)

${ }^{26}$ Tradução livre: Você pode mudar o foco dessa legislação para negros ou judeus e você poderia estar na Alemanha dos tempos de 1930 ou no apartheid da África do Sul entre 1950 e 1960. Era notoriamente errado em ambos os lugares e permanece errado aqui.
} 
éfundamental ao indicar a natureza híbrida das sociedades pós-coloniais, nas quais a relação entre o local e o global é muito mais complexa do que as narrativas estado-cêntricascarregadas de sentido colonial - geralmente incorporam.

Michael Shapiro também ressalta a importância da dimensão discursiva e nos leva a pensar sobre a mobilização de categorias, tendo em vista o legado histórico discursivo ainda persistente nessas dinâmicas. Como Shapiro (1984) comenta sobre Foucault (1984), o valor de um discurso não está na forma como ele pode ser validado em função do que trata, nem algo que deve ser compreendido nos termos de um conteúdo secreto. $\mathrm{O}$ valor do discurso reside nos tipos de recursos que ele oferece a particulares papeis de pessoas. Quem pode mobilizá-lo? Portanto, quando discutimos um projeto linguístico, temos que ser capazes de apontar: quem é um usuário privilegiado? (SHAPIRO, 1984). Com essas palavras, podemos levantar o questionamento do próprio espaço onde o discurso político se produz e opera. De acordo com Patrick Charaudeau (2008), a cenografia do poder, termo cunhado por ele, nos permite examinar como os espaços institucionais restringem as possibilidades de policy makers, seja através da força que a credibilidade opera junto a esses representantes ou os compromissos assumidos pela instância de representação política, nesse caso, as categorias restringentes de povo e nação.

Assim, qual a forma das territorialidades que insistem em promover um conjunto contraditório de discursos e práticas de sanção e, mais, quem carrega a autoridade e poder de mobilizar tal estrutura? Diante da exposição, o discurso de não financiamento da economia ugandense por parte de políticos em razão da alegada violação de direitos humanos está assentado no protagonismo econômico de Estados-nação particulares e que carregam o aporte econômico e simbólico necessário, em oposição a nações como Uganda, historicamente receptoras de recursos financeiros vinculados à ajuda humanitária e/ou cooperação ao desenvolvimento. A incorporação da dimensão de humilhação é, por sua vez, institucionalizada e desmembrada na verbalização desses enunciados.

O discurso de Barack Obama nos serve como um desses casos ao assumir o papel de modelo moral e de modernidade quando diz:

the Anti-Homosexuality Bill in Uganda, once law, will be more than an affront and a danger to the gay community in Uganda. It will be a step backward for all Ugandans and reflect poorly on Uganda's commitment to protecting the human rights of its people. It also will mark a serious setback for all those around the world who share a 
commitment to freedom, justice and equal rights. Enacting this legislation will complicate our valued relationship with Uganda. ${ }^{27}$

Longe de se limitar à ideia de um discurso pretensamente educativo, Carlos Milani (2016) mobiliza um questionamento fundamental para apontar a condicionalidade seletiva inclusa nessas narrativas. A condicionalidade como ferramenta normativa de políticas de cooperação para o desenvolvimento e/ou ajuda humanitária é geralmente abdicada a depender do grau de importância do país receptor. Nesses casos, os doadores realizam a cooperação, mesmo que aquele país não seja reconhecido como democrático e que não respeite os direitos humanos (MILANI, 2016). Nas palavras de Milani:

\begin{abstract}
A efetividade dessa norma é pífia do ponto de vista da agenda do desenvolvimento. Em que plano político ela é efetiva? Na humilhação. Sou contra qualquer forma de humilhação, seja ela de Estado, de ser humano de qualquer forma de organização. Penso que não é um instrumento do qual devemos fazer uso para fazer política. Essa lógica de utilização de condicionalidade política serve apenas para gestar, para produzir isso que denomino política de humilhação (MILANI, 2016, p. 167).
\end{abstract}

Esse processo ocorre em um enquadramento institucional de vigilância permitido através da exponencial visibilidade - ancorada nas ferramentas virtuais midiáticas e institucionais - como o exemplo dos discursos da agência das Nações Unidas para os Direitos Humanos $^{28}$. Neste caso em particular, o discurso de Navi Pillay, Alta Comissária da ONU para os direitos humanos, é representativo também ao não verbalizar a articulação externa nesse processo, não responsabilizando representantes estadunidenses pela internacionalização da homofobia autodeclarada ${ }^{29}$.

Diante desse cenário, a permanente associação entre a heterossexualização normativa e territorialidades africanas vem sendo retroalimentada pela visibilidade de processos de criminalização a sujeitos de sexualidades desamparados pelos instrumentos legais e a construção de discursos de cunho reducionista que insistem em associar nações africanas ao

\footnotetext{
${ }^{27}$ Tradução livre: A lei anti homossexualidade em Uganda, uma vez lei, será mais que um afrontamento e um perigo para a comunidade gay em Uganda. Representará um passo atrás para todos os ugandenses e refletirá negativamente sobre o comprometimento de Uganda em proteger os direitos humanos de seu povo. Também marcará um grave revés para todos aqueles que compram um compromisso com a liberdade, a justiça e a igualdade de direitos. A promulgação desta legislação complicará nosso valioso relacionamento com o Uganda. A permissão dessa legislação complicará o nosso valioso relacionamento com Uganda.

28 Esse é o caso de jornais como matérias produzidas por jornais como The Guardian que visibilizam e demarcam países modelos e países negativos para a convivência LGBTQ, como o caso da reportagem acessível em <https://www.theguardian.com/global-development-professionals-network/2017/mar/01/where-are-the-mostdifficult-places-in-the-world-to-be-gay-or-transgender-lgbt>

Discurso $\quad$ acessível em

〈http://www.ohchr.org/EN/NewsEvents/Pages/DisplayNews.aspx?NewsID=14275\&LangID=E>
} 
passo do atraso. Nesse sentido, como aponta Fernanda Bruno (2004), reaparece aqui a hipótese de que a produção de subjetividade é hoje marcada pela antecipação de projeção(BRUNO, 2004, p. 121).Dessa forma, a antecipação de Uganda como uma sociedade atrasada no imaginário sócio-discursivo impede mesmo o exercício de reflexão sobre a possibilidade de engajamento de grupos externos nesse processo, a ponto de reconhecermos a força de subjetividades na projeção das linguagens carregadas por sujeitos ideologicamente formados.

Sob esse prisma, é importante ressaltar o papel da visibilidade tanto midiática, bem como o lugar de discursos políticos proferidos em âmbito global, retroalimentados sob a subjetividade dos sujeitos. Portanto, a forma e o conteúdo de discursos, sobretudo daqueles que carregam a visibilidade pelo espaço político, projetam mecanismos regulatórios e normalizadores na designada "alma humana", como utiliza Foucault (1983), mas também possibilita um processo de disciplina institucionalizada em novos moldes sob programas de governos, por exemplo, que se aproveitam de seu protagonismo econômico e cultural como oportunidades de educar/docilizar um Outro historicamente racializado. Esse é o exemplo de governos como o da Dinamarca. Nas palavras de Mogens Jensen, Ministro de Comércio e Desenvolvimento, "We cannot distance ourselves too strongly from the law and the signal that the Ugandan government now sends to not only persecuted minority groups, but to the

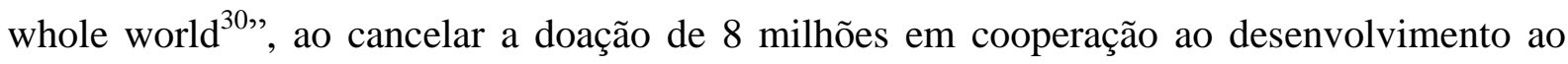
governo ugandense.

Em um mundo no qual a inserção de sujeitos e comunidades sociopolíticas em categorias sociais esquemáticas e a associação recorrente ao discurso do atraso ainda permanece, a visibilidade coletiva - incluindo a arquitetura de nações - culminam na constituição da subjetividade enquanto instância reducionista e hierarquizada. Essa articulação é sustentada pela retroalimentação entre visibilidade e subjetividade, reconhecendo-se a força difusa da cultura, da mídia, e, sobretudo, do legado histórico-cultural, nesse caso em particular. Notadamente, a articulação entre essas esferas - propiciada pelas tecnologias da informação e comunicação - é mister na contemporaneidade para que essa visibilidade, exposta em sua forma mais esquemática, engendre processos de antecipação e identificação de um sujeito e/ou um povo já proclamado como atrasado.

\section{Referências}

\footnotetext{
${ }^{30}$ Tradução livre: Não podemos nos distanciar na mesma medida da lei e do sinal que o governo ugandense envie agora não somente para grupos de minorias perseguidas, mas para o mundo inteiro.
} 
ALDRICH, Robert. Colonialism and Homosexuality. New York, Rouledge, 2003.

BAKHTIN, M./VOLOCHINOV, V. N. Marxismo e filosofia da linguagem. Tradução de Michel Lahud e Yara Frateschi Vieira. 9. ed. São Paulo: Hucitec, 1999 [1929-1930].

BHABHA, Homi. A questão do 'Outro': diferença, discriminação, e o discurso do colonialismo. Pós-Modernismo e Política. Editora Rocco, 1991.

O local da cultura. Belo Horizonte: Ed. UFMG, 1998.

BRUNO, F. Máquinas de Ver, Modos de Ser: visibilidade e subjetividades nas novas tecnologias de informação e comunicação. Revista FAMECOS. v. 24. Porto Alegre: 2004.

EPPRECHT, Marc. Heterosexual Africa?Nova York: Ohio University Press, 2008.

FOUCAULT, M. Arqueologia do saber. Trad. L. E. Baeta Neves. Petrópolis: Vozes,1971

HUMAN RIGHTS WATCH. This Alien Legacy: The Origins of "Sodomy" Laws in British Colonialism. New York, 2008.

MANZO, Kate: Critical Humanism: Postcolonialism and Postmodern Ethics. In: Moral Spaces. Rethinking Ethics and World Politics. Regents of the University of Minnesota, 1999.

FERNÁNDEZ, Marta. Uma Leitura Pós-Colonial sobre as "Novas" Operações de Paz da ONU: o caso da Somália. Tese (Doutorado em Relações Internacionais) - Instituto de Relações Internacionais/PUC-Rio, 2011.

MASCARO, Alysson. Estado e forma política. 1ªed. São Paulo: Boitempo, 2013

MILANI, Carlos. Entrevista Carlos Milani. In: Crises Humanitárias, Cooperação e o Papel do Brasil. Rio de Janeiro: Médicos Sem Fronteiras, 2016

MSIBI, T., The Lies We Have Been Told: On (Homo) Sexuality in Africa. Africa Today, Vol. 58, No. 1, 2011.

PUAR, JASBIR K. Homonacionalismo como Mosaico: viagens virais, sexualidades afetivas.In: Revista Lusófona de Estudos Culturais, vol. 3, n. 1, 2015.

RIBEIRO, Guilherme. Vidal de la Blache, ciência e política: notas a partir do caso africano. Confins [Online], 12. 2011.

SAID, Edward. Orientalismo: o Oriente como invenção do Ocidente. São Paulo: Companhia das Letras, 1990.

SHAPIRO, M. J. Language and politics. New York: New York University Press. 1984.

SPIVAK, Gayatri Chakravorty. Pode o subalterno falar? Tradução de Sandra Regina Goulart Almeida, Marcos Pereira Feitosa, André Pereira Feitosa. Belo Horizonte: EditoraUFMG, 2010, 133p. 
SOUZA, Marcelo Mendes. Mímica, Diferença e Repetição. Anuário de Literatura, v. 13, n. $1,2008$.

KAOMA, Kapya. Globalizing the Culture Wars: U.S. Conservatives, African Churches, \& Homophobia. Massachussets, 2009.

KAOMA, Kapya. Colonizing African Values: How the U.S. Christian Right is Transforming Sexual Politics in Africa. Massachussets, 2012.

KRISHNA, Sankaran: Globalization \& Postcolonialism. Hegemony and Resistance in the Twenty-first Century. Rowman \& Littlefield, 2009.

. "Kill The Gays": A Study of Homosexuality in Uganda. International Social Science Basic Studies, 2011.

Expanded Criminalisation of Homosexuality in Uganda: A Flawed Narrative. Sexual Minorities Uganda (SMUG).Kampala, 2014.

The Ugandan Anti-Homosexuality Bill: Study on how and to what extent the Bill violates human rights. How are homosexuality and the Bill perceived in Ugandan society? University of Oslo, 2014.

WALKER, R. B. J. Inside/Outside: International Relations as Political Theory. Cambridge, Cambridge University Press, 1993.

WILSON, Ara. Lesbian Visibility and Sexual Rights at Beijing. 1996 Disponível em 〈http://fds.duke.edu/db/attachment/409> 